\title{
The Seroprevalence of Viral Infections (HCV, HBV, HIV) in Hemodialysis in the Nephrology and Hemodialysis Department of UHC Point G, Bamako (Mali)
}

Samaké Magara ${ }^{1 *}$, Sy Seydou ${ }^{2}$, Coulibaly Kalilou ${ }^{3}$, Yattara Hamadoun ${ }^{2}$, Kodio Atabieme ${ }^{2}$, Coulibaly Moctar ${ }^{4}$, Dolo Aboudou Messoum ${ }^{5}$, Maiga Djénéba ${ }^{5}$, Sanogo Mamadou Badou ${ }^{2}$, Fofana Aboubacar Sidiki ${ }^{2}$, Diallo Djénéba ${ }^{2}$, Diarra Bakary $^{1}$, Fongoro Saharé ${ }^{2}$

\footnotetext{
${ }^{1}$ Nephrology Unit of the Fousseyni Daou Hospital in Kayes, Mali

${ }^{2}$ Nephrology and haemodialysis department of the UHC Point G, Bamako, Mali

${ }^{3}$ Nephrology Unit of the Somino DOLO in Mopti, Mali

${ }^{4}$ Nephrology Unit of the Mali Gavardo Hospital of Sébénikoro, Bamako, Mali

${ }^{5}$ Nephrology Unit of the Sikasso, Mali
}

DOI: $10.36347 /$ sasjm.2020.v06i05.001

| Received: 03.04.2020 | Accepted: 11.04.2020 | Published: 04.05.2020

*Corresponding author: Samaké Magara

Introduction: Viral infections, especially those caused by the hepatitis $\mathrm{C}$ virus (HCV), hepatitis $\mathrm{B}$ and that of human immunodeficiency HIV, are common in patients undergoing chronic hemodialysis. Objectives: to determine the prevalence of anti-HCV, anti-HIV and HBs antigen antibodies in chronic hemodialysis patients in the nephrology and hemodialysis department of the UHC Point G. Methodology: This was a retrospective study, carried out from January 1 to December 31, 2015 in the nephrology and hemodialysis service of the UHC Point G. Were included, all chronic hemodialysis patients for 3 months and more having carried out viral serologies of hepatitis B, C and HIV. Results: We collected 45 patients, the female sex represented $57.8 \%$ with a sex ratio of 0.73 . The average age was 37.61 years with extremes of 16 and 78 years. The detection of anti HCV, anti HIV and HBs antigen antibodies was positive in 4 , 9 and 2 patients, respectively, with prevalence rates of $9 \%, 20 \%$ and $4 \%$, respectively. The prevalence of hepatitis $\mathrm{C}$ was higher in patients whose duration on dialysis is between 3-6 years $(p=0.021)$, (see Table-1). The prevalence of HIV infection was also correlated with the duration of hemodialysis greater than 1 year for HIV $(p=0.010)$. We found two cases of hepatitis B and C coinfection and one case of hepatitis B and HIV coinfection. Blood transfusion was performed in $95.5 \%$ of the patients. On multivariate analysis, there was no statistically significant relationship between blood transfusion and these different viral infections [HCV $(p=0.647)$, HBV $(p=0.289), H I V(p=0.752)$ ]. Conclusion: this study has highlighted the frequency of viral infections with hepatitis B, C and HIV in our hemodialysis patients. They must be prevented by rigorous control of the blood transfusion circuit, strict observance of hygiene rules and the recruitment of qualified personnel and in sufficient numbers.

Keywords: Prevalence, hepatitis B and C, HIV, hemodialysis, Mali.

Copyright @ 2020: This is an open-access article distributed under the terms of the Creative Commons Attribution license which permits unrestricted use, distribution, and reproduction in any medium for non-commercial use (NonCommercial, or CC-BY-NC) provided the original author and source are credited.

\section{INTRODUCTION}

Viral infections, particularly those caused by the hepatitis C virus (HCV), hepatitis B and that of the human immunodeficiency virus, are frequent in patients subjected to chronic hemodialysis. Hepatitis $\mathrm{C}$ remains the main infection in hemodialysis patients. Its prevalence varies between 10 and $65 \%$ depending on the geographic area, and it is significantly correlated with the duration of dialysis and the number of blood products transfused [1]. Transmission of hepatitis C is predominantly associated with non-compliance with universal hygiene rules, and transmission through dialysis equipment is anecdotal [2]. The severity of this infection lies in its high risk of progression to chronicity and the development of cirrhosis or hepatocarcinoma [3]. Routine vaccination of patients with chronic renal failure against $\mathrm{HBV}$ has significantly reduced its prevalence in these patients [4]. In Mali, there is little data related to the prevalence of these infections in hemodialysis patients, hence the interest of this study; with like objectives, to determine the prevalence of anti-HCV, anti-HIV and $\mathrm{HBs}$ antigen antibodies in chronic hemodialysis patients in the nephrology and hemodialysis department of the UHC Point G. 


\section{METHODOLOGY}

This was a retrospective study, from January 1 to November 31, 2015 (11 months). Included were all chronic hemodialysis patients for three (03) months in the nephrology and hemodialysis department having performed viral serologies of hepatitis B, C and HIV. For each patient selected, epidemiological, clinical, paraclinical, therapeutic and evolutionary data were listed from individual medical records.

The hemodialysis unit has thirty (30) stations where two hundred and eighty-five (285) dialysis patients are currently on dialysis. The center staff includes three nephrologist doctors, nine nurses (6 permanent and 3 volunteers) and three laborers. The search for anti-HCV antibodies was carried out with the HCV Cypress test (Cypress Diagnostics) or the HCV Tri-dot test (J. Mitra and Co Pvt. Ltd). The Alere HIV Combo test (Alere medical Co., Ltd. Japan) was used to test for the P24 antigen and antibodies associated with the HIV-1 and / or HIV-2 viruses. The hepatitis B virus (Ag HBs) surface antigen was tested using the Ag Cypress test (Cypress Diagnostics). The sensitivity of these different tests varied between $95.16 \%$ and $100 \%$ and the specificity between $96.30 \%$ and $99.95 \%$.

Strict respect for the anonymity of the files was observed. The entry was made on WORD 2010 and the data analysis on SPSS20.0. The statistical test used is Pearson's Chi-square with $\mathrm{p}<0.05$ (significance value).

\section{RESULTS}

We collected 45 patients, the female sex represented $57.8 \%$ with a sex ratio of 0.73 . The average age was 37.61 years with extremes of 16 and 78 years. Among the 45 hemodialysis patients; anti-HCV, antiHIV and HBsAg antibodies were tested positive in 4, 2 and 9 patients, respectively, with prevalence rates of $9 \%, 4 \%$ and $20 \%$, respectively. Patients with a hemodialysis duration between 1-3 years were in the majority, $42.22 \%$ of cases. The prevalence of hepatitis $\mathrm{C}$ was higher in patients whose duration on dialysis is between 3-6 years $(\mathrm{p}=0.021)$, (see Table-1). The prevalence of HIV infection was also correlated with the duration of hemodialysis greater than 1 year for HIV ( $p=0.010)$. In contrast, there was no statistically significant relationship between duration of hemodialysis and viral hepatitis B infection $(\mathrm{p}=0.478)$. We found two cases of hepatitis $\mathrm{B}$ and $\mathrm{C}$ coinfection and one case of hepatitis B and HIV coinfection.

The initial nephropathy was glomerular $(48.89 \%)$, vascular $(35.56 \%)$, hereditary $(6.67 \%)$ (see Table-2). Clinical signs were represented by: Physical asthenia and weight loss in $75.6 \%$ for each, followed by hepatomegaly (35.6\%), generalized pruritus (33.3\%), collateral venous circulation $(11,1 \%)$, jaundice $(6.7 \%)$ and internal hemorrhoids (6.7\%). Eighty-four point four percent $(84.4 \%)$ of patients were on dialysis for arteriovenous fistulas. Blood transfusion was performed in $95.5 \%$ of the patients. On multivariate analysis, there was no statistically significant relationship between blood transfusion and these different viral infections [HCV ( $\mathrm{p}=0.647), \operatorname{HBV}(\mathrm{p}=0.289), \operatorname{HIV}(\mathrm{p}=0.752)]$. Total bilirubin was high in 44 and $75 \%$, respectively, in patients infected with hepatitis B virus and C. ALAT and ASAT were high in all patients with anti-HCV positive antibody $(100 \%)$ and in $78 \%$ of patients with positive HBs antigen.

Table-1: Distribution of patients by duration of hemodialysis and HCV infection

\begin{tabular}{|l|l|l|l|l|l|l|}
\hline \multicolumn{2}{|c|}{} & \multicolumn{3}{|c|}{ Duration on hemodialysis } & \multirow{2}{*}{ Total } \\
\cline { 3 - 6 } \multicolumn{2}{|c|}{} & $<1$ year & $\mathbf{1 - 3}$ years & 3-6 years & >6 years & \\
\hline \multirow{2}{*}{ VHC } & Positive & $0(0,0 \%)$ & $1(5 \%)$ & $2(18,2 \%)$ & $1(50 \%)$ & $4(9 \%)$ \\
\cline { 2 - 6 } & Negative & $12(100 \%)$ & $18(95 \%)$ & $9(81,8 \%)$ & $1(50 \%)$ & $40(91 \%)$ \\
\hline \multicolumn{2}{|l|}{ Total } & $12(100 \%)$ & $19(100 \%)$ & $11(100 \%)$ & $2(50 \%)$ & $44(100,0 \%)$ \\
\hline
\end{tabular}

Table-2: Distribution of patients according to initial nephropathy

\begin{tabular}{|l|l|l|}
\hline Initial nephropathy & Workforce & Percentage \\
\hline Glomerular nephropathy & 22 & $48,89 \%$ \\
\hline Vascular nephropathy & 16 & $35,56 \%$ \\
\hline Hereditary nephropathy & 3 & $6,67 \%$ \\
\hline Diabetes & 3 & $6,67 \%$ \\
\hline Ischemic nephropathy & 1 & $2,22 \%$ \\
\hline Total & 45 & $100 \%$ \\
\hline
\end{tabular}

\section{DISCUSSION}

Limitations of the study: low sampling due to the low socio-economic standard of living of certain patients, limiting the carrying out of certain additional examinations (transaminases, bilirubinemia, prothrombin level, viral load) because of their high cost.

\section{Hepatitis C}

The prevalence of hepatitis is $9 \%$ in our series. It is very variable according to the studies, ranging from 4.3\% to $78 \%$ according to Agarwal et al., in India and Kawtar Boulaajaj et al., in Morocco [3,5]. The increase in transaminases was observed in all of our patients. On the other hand, in the literature it was only observed in 
one third of hemodialysis patients [6]. Transaminases are therefore not very informative in patients with chronic renal failure and it is important, if there is a suspicion of $\mathrm{HCV}$ infection, to perform a serology immediately or better, a PCR [7].

\section{Hepatitis B}

Its high prevalence $(20 \%)$ is explained, on the one hand, by the non-systematization of the vaccination of chronic renal failure patients before the start of dialysis linked to the often late recourse of patients to a nephrological consultation. This prevalence was $45 \%$ before the systematization of vaccination in 1980, in relation to its epidemiology, and its preferential modes of parenteral and nosocomial contamination [7]. And on the other hand, by the high frequency of blood transfusions, the non-use of agents stimulating erythropoiesis, the deficit of medical staff and recurrent ruptures of hygiene and protective equipment; making it difficult to strictly adhere to universal hygiene rules. Total bilirubinemia and transaminases were elevated in 44 and $78 \%$ of patients with $\mathrm{HBsAg}$ positive, respectively. Contemporary biological abnormalities of $\mathrm{HBV}$ infection in dialysis patients are less frequent than in the general population, and transaminases are normal in more than half of the cases despite proven viral replication [7].

\section{HIV}

Its prevalence is $4 \%$ in our study. This rate is proportionally higher compared to several studies which report low rates, see zero of HIV infection in hemodialysis patients [3, 8, 9]. It is linked to the duration of hemodialysis greater than 1 year $(\mathrm{p}=$ 0.010). This could be explained by the lack of qualified personnel at our center, favoring non-compliance with the usual hygiene rules and a lack of maintenance of the generators and accessories. In Casablanca, there was a significant correlation between HIV infection in hemodialysis patients and blood donors [10].

\section{PREVENTION}

In hemodialysis patients, the risk of viral infection is foreseeable, taking into account the immunodeficiency induced by insufficiency, the use of the same device for several patients whose total disinfection is impossible, from secondary risk to non respect of the rules of hygiene and the risk of contamination evaluated at $30 \%$ of unknown cause. Chronic hemodialysis patients have a significant risk of infection which increases with the duration of hemodialysis. Prevention takes place at several levels, that of the patient and the care gestures on which he is dependent in the context of his treatment and dialysis equipment. We must therefore strive to supervise preventive measures in all these directions [11].

\section{Prevention of Viral Hepatitis C}

It is essential to take preventive measures to transmit viral hepatitis $\mathrm{C}$ in dialysis centers, especially since there is no vaccine.

\section{Prophylactic Measures in Dialysis Centers}

The most effective attitude to reduce the transmission of $\mathrm{HCV}$ is the strict observance of the universal rules of hygiene which rest on the washing of the hands, the use of gloves and disposable fields, the change of gloves for each patient, the disinfection of machines after each session and eviction of any contamination of the circuit with blood [12-14]. Systematic and repeated screening for anti-HCV antibodies in all hemodialysis patients [15].

The dialysis environment: the premises must be spacious with a number of machines adapted to the number of patients and the number of staff. Maintaining the environment requires a strict organization of hemodialysis sessions, as well as connection and disconnection schedules for patients so that cleaning can be done correctly on all the surfaces affected in the usual way, between each patient, at the end of the daily program and at the end of the week. Finally, the waste must be immediately disposed of $[11,14]$.

Encourage the treatment of chronic renal failure by peritoneal dialysis or by hemodialysis at home: the prevalence of viral infections by this technique and by the use of a personal machine is much lower [16, 17]. Kidney transplantation as early as possible also reduces the risk of contamination $[15,18]$.

\section{Reducing The Risk Linked To Blood Transfusions}

Screening has considerably reduced the risk of viral transmission. The residual risk of viral transmission essentially results from the serological window which is $1 / 400,000$ bags transfused [19]. As for the interrogation of blood donors, it will eliminate those who are at risk, even if most often, the symptomatology of hepatitis $\mathrm{C}$ is not obvious. Recombinant human erythropoietin tends to replace blood transfusions thus avoiding the risk of contamination, but its prohibitive cost does not allow this country. The use of specific devices for hemodialysis patients with anti-HCV antibodies: this recommendation made in order to protect those who are free [20] seems questionable for various reasons [21]:

- Logistical difficulties and significant additional cost.

- The identification of all contaminating patients and their isolation are difficult due to the serological window which can be six months.

- Using the same machine for patients with anti$\mathrm{HCV}$ antibodies may increase the risk of superinfection with other strains of $\mathrm{HCV}$ due to the high genomic variability of the virus. 


\section{Prevention of Viral Hepatitis B}

The prevention of HBV infection is based on compliance with the rules of universal hygiene and on vaccination against $\mathrm{HBV}$ :

- $\mathrm{HBV}$ is transmitted mainly through healthcare equipment or through the hands of staff. Surfaces or equipment can be contaminated in the absence of visible blood [23]. Thus, compliance with universal hygiene rules and the separation of infected and non-infected patients makes it possible to eliminate the nosocomial risk.

- HBV infection remains the viral infection most often transmitted by blood transfusion with a risk of contamination of 1 / 200,000 bags transfused due to the serological window. Erythropoietin should therefore replace blood transfusions but its high cost limits its prescription, especially in our country.

- Vaccination is effective and will be offered to all subjects developing renal insufficiency. Even if any immune deficiency, including renal insufficiency, an age greater than 40 years or the male sex, decrease the immunogenicity of the vaccination, its indication is maintained (four intra-deltoidian injections as a primary vaccination, a booster at one year) because it allows the protection of $70 \%$ of hemodialysis patients. No case of chronic HBV infection has been reported after vaccination, even in non-responders, suggesting that despite the absence of an effective anti-HBs response, protection against the risk of chronic infection is possible [24].

\section{Prevention of HIV infection}

The risk of transmission of HIV infection from one patient to another is almost zero subject to the application of strict hygiene rules [25]. However, noncompliance with these rules can have catastrophic consequences in the dialysis unit: in 1994, the Atlanta CDC reported seven HIV seroconversions in a dialysis center in a developing country that re-used needles between each session [26]. The usual disinfection and sterilization measures, as well as the use of disposable equipment, are sufficient to prevent any risk of transmission of the virus during dialysis [27]. However, the risk of HIV transmission through accidental exposure is a constant concern in dialysis centers. This risk is estimated at $0.3 \%$ for HIV but remains less than the contagiousness of around $30 \%$ of hepatitis B [28].

\section{CONCLUSION}

This study made it possible to highlight the frequency of viral infections with hepatitis B, C and HIV in our hemodialysis patients. They must be prevented by rigorous control of the blood transfusion circuit, strict observance of hygiene rules and the recruitment of qualified personnel and in sufficient numbers.
Conflict of interest: None.

\section{REFERENCES}

1. Chan TM, Lok AS, Cheng IK, and Chan RT. Prevalence of hepatitis $\mathrm{C}$ virus infection in hemodialysis patients: longitudinal study comparing the results of RNA and antibody assays. Hepatology. 1993; 17:5-8

2. Allander T, Medin C, Jacobson SH, Grillner L, Persson MA. Hepatitis $\mathrm{C}$ transmission in a hemodialysis unit: molecular evidence for spread of virus among patients not sharing equipement. JMed Virol. $1994 ; 43: 415-9$

3. Boulaajaj K, Elomari Y, Elmaliki B, Madkouri B, Zaid D, Benchemsi N. Infections virales: VHC, VHB et VIH chez les hémodialyses, CHU IbnRochd, Casablanca. Néphrologie \& thérapeutique. 2005 Nov 1;1(5):274-84

4. Crosnier J, Jungers P, Courouce AM, Laplanche A, Benhamou E, Degos F. Radomised placebocontrolled trial of hepatitis B surface antigen vaccine in french haemodialysis unit: II. haemodialysis patients lancet. 1981;1:797-800.

5. Agarwal SK, Dash SC, Irshad M. Hepatitis C virus infection during hemodialysis in India. J Assoc Physicians India. 1999 Dec; 47(12): 113943

6. Pereira BJ, Levey AS. Hepatitis C virus infection in dialysis and renal transplantation. Kidney int. 1997;51:981-99

7. Anaïs Vallet-Pichard, Stanislas Pol. Management of hepatitis $\mathrm{B}$ or $\mathrm{C}$ virus infection in patients with chronic renal failure. Nephrology \& Therapeutics. 2015; 11: 507-520.

8. Boulaajaj K, Elomari Y, Elmaliki B, Madkouri B, Zaid D, Benchemsi N. Infections virales: VHC, VHB et VIH chez les hémodialyses, CHU IbnRochd, Casablanca. Néphrologie \& thérapeutique. 2005 Nov 1;1(5):274-84.

9. Poignet JL, Desassis JF, Chanton N. Prevalence of HIV infection in dialysis patients. Results of a national multicenter survey. Nephrology. 1999; 20: 3 .

10. Abacioglu YH, Bacaksizf, Bahar IH. Molecular evidence of nosocomial transmission of hepatitis C virus in a haemodialysis unit. Eur J Clin Microbiol Infect Dis. 2000; 19:182-6.

11. Casablanca regional blood transfusion center (RBTC). Statistics. 2002 (submitted by RBTC)

12. Simon N. hepatitis $C$ virus on hemodialysis. Path Rial. 1995; 735-40.

13. Fontaine H, Pol S. Prevention and treatment of viral hepatitis in renal failure situations. Nephrology. 2001; 22(7): 339-47.

14. Jadoul M, Cornu C, de Strihou CV, Group UC. Universal precautions prevent hepatitis $\mathrm{C}$ virus transmission: a 54 month follow-up of the Belgian multicenter study. Kidney international. 1998 Apr $1 ; 53(4): 1022-5$. 
15. Malavaud S, Marty N. In: prevention of the nosocomial risk linked to the hepatitis $\mathrm{C}$ and $\mathrm{G}$ viruses. The letter from the infectiologist - Tome XIV ${ }^{\circ}{ }^{\circ}$ 2. February 1999.

16. Hachicha J, Hammami A, Masmoudi H, Hamida MB. Viral hepatitis $\mathrm{C}$ in chronic hemodialysis patients in southern Tunisia. Internal Ann Med (Paris). 1995; 146 (5): 295-8.

17. Buisson C, Degos F, Daniel F. Pharmacocinetics of interferon alpha-28 in hémodialysis. Nephrol Dial Transplant. 1994; 9 :977-8 (abstract).

18. Durand PY, Chantiau J, Gamberoni J. In: prevalence of hepatitis $\mathrm{C}$ on peritoneal dialysis in France: results of a multicenter study in France. XWVIè symposium. Saint-Etienne: Gambro. 1995: 97-103.

19. Quzand. What are the precautions for hepatitis C? Gastroenterol Clin Biol. 1997: 21.

20. Plan National Viral B et C (2002-2005) France.www.hepatoweb.com/hepatobase/hepatite O.html

21. Loureiro A, Macedo G, Pinto T. hepatitis C virus in hemodialysis patients: lesions from epidemiology and prophylaxis. Nephrol Dial Transplant. $1995 ; 10(6): 83-7$
22. Jadoul M, Wrist JL. Prevention of hepatitis C virus transmission on hemodialysis. Nephrology. 1997; 18: $307-8$

23. Furrer H, Kiss D, Liest AL. Hemodialysis: viral infections transmitted by blood. Swiss NOSO. 1996; 3(3)

24. Pol S. Hepatitis B, hemodialysis and renal transplantation: prevention and treatment. 5th Day of News in Hepatogastroenterology Paris 1999.

25. Fromentin L, Michel C, Viron B. Extra-renal purification of chronic renal failure infected with HIV. Press Med. 1993; 22: 13-8

26. Velandia M, Fridkin S, Cardenas V. Human immuno-deficiency virus transmission in a Developping Countrys Dialysis Center. Lancet. 1995 ; $345: 1417-22$

27. Poignet JL, Desassis JF, Chanton N. Prevalence of HIV infection in dialysis patients: results of a national multicenter survey. Nephrology. 1999; 20: 3

28. National public health network. Circular on the transmission of infectious agents carried by blood or other biological fluids during treatment. BEH. 1998; 25: 107-11. 